\title{
An underappreciated risk of an airway exchange catheter
}

\author{
Julena Foglia, MD (D) John Guy, MD, FRCPC
}

Received: 23 September 2019/Revised: 8 October 2019/Accepted: 8 October 2019/Published online: 11 October 2019

(C) Canadian Anesthesiologists' Society 2019

\section{To the Editor,}

The airway exchange catheter (AEC) is a valuable tool to facilitate safe endotracheal tube (ETT) exchange, ${ }^{1}$ and has been incorporated into the Difficult Airway Society algorithm for stepwise extubation of known difficult airways. $^{2}$ Despite its reported successes, the potential for complications from AEC use must be understood. The most common complications reported include airway injury (including tracheal-bronchial disruption), pneumothorax, as well as the loss of airway. ${ }^{3-5}$ Failure rates for single-lumen ETT exchanges have been reported to be as high as $9.3 \% .^{4}$

Herein, we present a unique experience during a case for mandibular fixation with postoperative jaw wires where a failed ETT exchange with an AEC resulted in a near loss of the airway. Written consent was obtained prior to the composure of this letter. The patient was a 56 yr-old healthy adult male who obtained isolated facial injuries after a mechanical fall resulting in bilateral anterior mandible fractures and a right condylar fracture. An awake nasal flexible bronchoscopic (FB) technique was used to secure the airway with a size 8.0 Parker Flex-Tip ${ }^{\circledR}$ (Model: H-PFHV-80, Parker Medical; Highlands Ranch, CO, USA) ETT. There was a moderate amount of dried blood and minor oropharyngeal bleeding, but visualization was adequate, and FB-assisted nasal intubation was uneventful. Approximately two minutes after the ETT

J. Foglia, MD (ه) .

Department of Anesthesiology, Pharmacology, \& Therapeutics, University of British Columbia, Vancouver, BC, Canada

e-mail: julenafoglia@alumni.ubc.ca

J. Guy, MD, FRCPC

Royal Inland Hospital, Kamloops, BC, Canada was secured, there were difficulties with ventilation due to an air leak from a ruptured ETT cuff. To facilitate ETT exchange, an $83 \mathrm{~cm}$ long Cook Airway Exchange Catheter (Model: C-CAE-19.0-83, Cook Medical; Bloomington, IN, USA) was gently advanced inside the ETT until resistance was met. Immediately after, two attempts at pulling the ETT over the AEC were met with resistance preventing the ETT from being removed.

Subsequently, a Glidescope ${ }^{\circledR}$ (Model: Video monitor 0570-0338 with LoPro 3 blade, Verathon Medical (Canada) ULC; Burnaby, BC, Canada) was cautiously inserted to assess the supraglottic area. As seen in the Figure, the tip of the AEC had passed through the murphy eye of the ETT, and then in a retrograde manner had looped back on itself and kinked in the trachea. Seeing this tortuous path of the AEC, we attempted to pull back the AEC into the ETT. Nevertheless, significant resistance was met because of kinking of the AEC at the ETT murphy eye. Therefore, under Glidescope ${ }^{\circledR}$ guidance, the kinked AEC and ETT were removed en bloc and the patient was successfully re-intubated orally. The patient was followed up postoperatively for five days, and there were no apparent sequelae.

The use of AECs are frequently seen in clinically difficult airway scenarios. As we have described, the catheter can exit through the murphy eye of an ETT. This misdirected exit can impede the withdrawal of the ETT over the AEC leading to an inability to withdraw the AEC and/or the ETT itself. This rare complication can lead to loss of an airway. When using the AEC for either staged extubation or ETT exchange, a misdirected AEC should be included in the differential diagnosis for high resistance during AEC and/or ETT removal. 


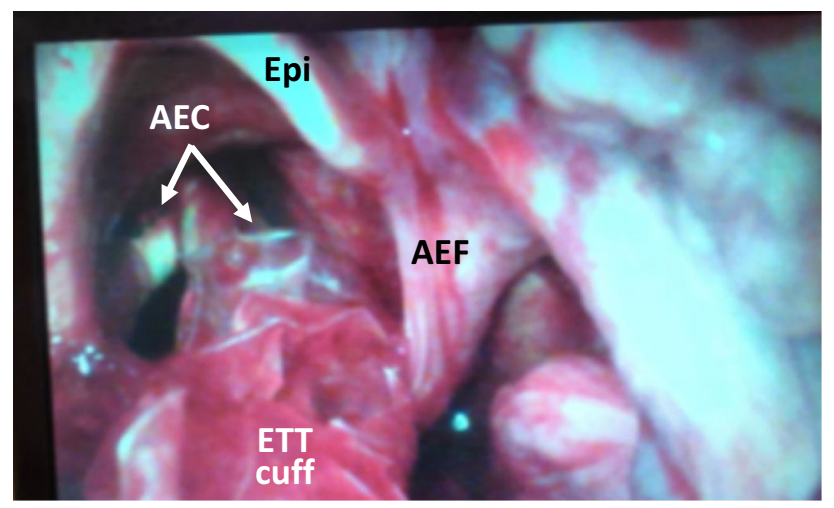

Figure A videolaryngoscopic view of a previously nasally intubated patient with mandibular fractures who required endotracheal tube (ETT) exchange because of a cuff leak. A Cook Airway Exchange Catheter ${ }^{\circledR}$ can be seen looping retrogradely into the trachea through the murphy eye of the ETT and folding on itself. Blood on the ETT cuff was from initial traumatic facial injuries. AEC $=$ airway exchange catheter; $\mathrm{AEF}=$ aryepiglottic fold; Epi = epiglottis; ETT cuff $=$ endotracheal tube

Financial disclosure The authors have no financial disclosures as the composure of this manuscript did not receive funding. The authors also do not have commercial or non-commercial affiliations.
Editorial responsibility This submission was handled by Dr. Hilary P. Grocott, Editor-in-Chief, Canadian Journal of Anesthesia.

\section{References}

1. Kim EJ, Yoon JY, Woo MN, Kim CH, Yoon JU, Jeon DN. Damage to the pilot balloon of the nasotracheal tube during orthognathic double-jaw surgery: A case report. J Dent Anesth Pain Med 2015; 15: 101-3.

2. Difficult Airway Society Extubation Guidelines Group, Popat M, Mitchell $V$, et al. Difficult Airway Society Guidelines for the management of tracheal extubation. Anaesthesia 2012; 67: 318-40.

3. McLean S, Lanam CR, Benedict W, Kirkpatrick $N$, Kheterpal S, Ramachandran $S K$. Airway exchange failure and complications with the use of the Cook Airway Exchange Catheter ${ }^{\circledR}$ : a single center cohort study of 1177 patients. Anesth Analg 2013; 117: $1325-7$.

4. Rashid AM, Williams C, Noble J, Rashid OM, Takabe K, Anand $R J$. Pneumothorax, an underappreciated complication with an airway exchange catheter. J Thorac Dis 2012; 4: 659-62.

5. Mort TC. Continuous airway access for the difficult extubation: the efficacy of the airway exchange catheter. Anesth Analg 2007; 105: $1357-62$.

Publisher's Note Springer Nature remains neutral with regard to jurisdictional claims in published maps and institutional affiliations. 